Original

Article

\section{Clinical features and prognostic factors of early breast cancer at a major cancer center in North India}

\author{
Raina Vinod, Bhutani Manisha, Bedi Rajeev, Sharma Atul, Deo Suryanarayana V. S*, \\ Shukla Nootan $\mathrm{K}^{\star}$, Mohanti Bidhu Kalyan ${ }^{\star \star}$, Rath Goura $\mathrm{K}^{\star \star}$ \\ Departments of Medical Oncology, *Surgical Oncology, and ${ }^{* *}$ Radiation Oncology, Institute Rotary \\ Cancer Hospital, All India Institute of Medical Sciences, New Delhi - 110029, India
}

Correspondence to: Dr. Vinod Raina, E-mail: vinodraina@hotmail.com

\begin{abstract}
BACKGROUND: Data on the clinical profile of early breast cancer (EBC) from India is scant. Due to differences in genetics, environment, lifestyle, socio-demographic structure and ethnicity, the presentation and behavior of breast cancer in India may be different. AIMS: To analyze the clinical presentation and outcome of EBC patients. SETTINGS AND DESIGN: A single center retrospective study. MATERIALS AND METHODS: Data from 487 EBC patients registered and treated at our institute from 1993 through 1999 were analyzed. Cox's multivariate regression test was used to determine prognostic factors for overall and disease-free survival (OS \& DFS). RESULTS: The median age was 47 years and $49.7 \%$ patients were pre-menopausal. Ninety-six per cent patients presented with a lump. Stages I, Ila, and IIb comprised $7.8 \%, 38.8 \%$, and $47.6 \%$ respectively. Only $11.3 \%$ patients opted for breast-conserving surgery (BCS) while the remaining $88.7 \%$ underwent modified radical mastectomy (MRM). Adjuvant chemotherapy was administered to 275 (56.5\%), and radiotherapy to 146 (29.9\%). Estrogen receptor status was known in 173, of whom 93 (53.7\%) were positive. Most patients were prescribed Tamoxifen for 5 years. At a median follow-up of 48 months, 126 (25.9\%) patients had relapsed (systemic 107, loco-regional 19) and 94 (19.3\%) had died. Five-year DFS and OS were $73 \%$ and $78 \%$, respectively. On multivariate analysis, $\geq$ four positive nodes adversely influenced survival $(P<0.01)$. CONCLUSIONS: The median age at presentation was 47 years, significantly lower than most Western figures. The majority $(86.4 \%)$ had a lump size $>$ two $\mathrm{cm}$. BCS was done in only $11 \%$ and the rest underwent MRM. Nodal involvement was the significant prognostic factor.
\end{abstract}

Key Words: Breast cancer, India, epidemiology, prognosis

\section{Introduction}

The age-standardized rates of breast cancer in India are significantly lower, almost one quarter to one-third of those in North America and Europe respectively. ${ }^{[1]}$ The postulated reasons for the lower incidence of this disease are believed to be lower socioeconomic status, delayed menarche (14 years vs. 12.6 years in white women), relatively early age at birth of first child, high parity and nearly universal and prolonged breast-feeding. However, the mortality rates are proportionally higher, with an incidence/mortality ratio of 0.48 compared with 0.25 in North America. ${ }^{[2]}$ Late diagnosis is a major factor for increased mortality as the majority of the patients present in advanced or metastatic stage. This is primarily attributed to lack of access to medical facilities, virtually non-existent breast cancer screening programs, lack of awareness and social-cultural attitudes. Accordingly, five-year survival rates have been poorer, reported as $42 \%$ and $48 \%$ in two population-based 
studies. ${ }^{[3,4]}$ Early breast cancer (EBC) constitutes about $30 \%$ of the breast cancer load in our country. ${ }^{[5]}$ There is no published case series on EBC from India. We undertook this study to analyze the presentation and outcome of EBC in a major cancer center in North India.

\section{Materials and Methods}

Case records of all the female patients registered at the Breast Cancer Clinic at our institute over a seven-year period from January 1993 to December 1999 were retrieved. EBC was defined as tumors of less than five centimeters ( $\mathrm{T} 1, \mathrm{~T} 2)$, with either impalpable (N0) or palpable (N1) but not fixed lymph nodes with no evidence of distant metastases (M0), corresponding to Stages I and IIa by AJCC/UICC TNM classification. ${ }^{[6]}$ Patients with tumors more than five $\mathrm{cm}$ (T3) were included if they had N0 M0 disease, Stage IIb. All EBC cases with pathological confirmation either by fine needle aspiration cytology or core biopsy and who had been treated by at least one mode of treatment (surgery, chemotherapy or radiotherapy) were included in the analysis. Data from 487 patients were thus analyzed. A proforma was completed for each patient that included social, demographic, clinical, and treatment profile. All patients were followed up every three months after completion of initial treatment and those who failed to attend were contacted by phone or by personal visits. Data available as of May 2001 were used for the analysis of end-points and survival. So the last year of follow-up was 2001.

\section{Statistical methods}

The association between the characteristics of the patients and survival was evaluated with a Cox-model in univariate and multivariate analysis. Disease-free survival (DFS) was defined as the interval from the date of surgery to relapse, the appearance of a second primary cancer (including a contralateral breast cancer) or death, whichever occurred first. Overall survival (OS) was defined as the interval from the date of diagnosis to death or last contact with the patient. Cumulative survival curves were estimated using the Kaplan-Meier method and compared using the log-rank test. Twotailed probability $(P)$ values of $\leq 0.05$ were regarded as significant. Exact $P$ values were reported only when $P \geq$ 0.01 .

\section{Results}

The median age was 47 years (range $23-82$ years), 242 $(49.7 \%)$ women were pre-menopausal and 236 (48.5\%) postmenopausal and for nine the menopausal status was unknown. Median ages at menarche and menopause were 14 years (range $12-17$ years) and 46 years (36-56 years), respectively. Thirty-four patients (7\%) had a first-degree relative with history of breast cancer. Four hundred and seventy women $(96.5 \%)$ presented with breast lump, 77 (15.8\%) had pain and 24 (4.9\%) had nipple discharge in addition. Details of clinical and pathological staging are shown in Table 1.

All patients underwent surgery; 258 (52.9\%) were operated on in other hospitals and then referred to our center for further management. Eighty-four (17.2\%) out of these required an additional surgical procedure due to inadequate or close margins or inadequate axillary clearance. Modified radical mastectomy (Patey's) was the commonest procedure performed in 432 $(88.7 \%)$ patients, and breast-conserving surgery (BCS) was carried out in $55(11.3 \%)$ patients. Invasive ductal carcinoma was the commonest histology in 452 (92.8\%) patients followed by invasive lobular carcinoma in $14(2.9 \%)$, and medullary carcinoma in seven $(1.4 \%)$.

Adjuvant radiotherapy was given to 146 (29.9\%) patients; indications included T3 tumor size, $\geq 4$ positive axillary nodes, positive margins, and BCS. Chemotherapy was administered to 275 (56.5\%) women. Most of the patients $(n=250)$ were given CMF regimen (cyclophosphamide, methotrexate and 5fluorouracil) and 25 (9.1\%) received anthracycline-based chemotherapy. Estrogen receptor (ER) status was known for only 173 women of whom 93 (53.7\%)

Table 1: Clinical and pathological staging of 487 early breast cancer cases

\begin{tabular}{lrrrr} 
Staging & \multicolumn{2}{c}{ Clinical } & \multicolumn{2}{c}{ Pathological } \\
Tumor size & No. Patients (\%) & \multicolumn{2}{c}{ No. Patients (\%) } \\
\hline T1 & 55 & $(11.3)$ & 134 & $(27.5)$ \\
\hline T2 & 361 & $(74.1)$ & 298 & $(61.2)$ \\
\hline T3 & 60 & $(12.3)$ & 29 & $(6.0)$ \\
\hline Tx & 11 & $(2.3)$ & 26 & $(5.3)$ \\
\hline Nodal status & & & & \\
\hline N0 & 254 & $(52.2)$ & 246 & $(50.5)$ \\
\hline N1 & 225 & $(46.2)$ & 217 & $(44.6)$ \\
\hline Nx & 8 & $(1.6)$ & 24 & $(4.9)$ \\
\hline Stage & 38 & $(7.8)$ & 79 & $(16.2)$ \\
\hline I & 189 & $(38.8)$ & 180 & $(37.0)$ \\
\hline II a & 232 & $(47.6)$ & 183 & $(37.6)$ \\
\hline II b & 21 & $(4.3)$ & None & \\
\hline III & 7 & $(1.4)$ & 45 & $(9.2)$ \\
\hline Unknown & & & &
\end{tabular}


were positive. Most patients therefore had unknown ER status and, as was the practice at that time, were also prescribed Tamoxifen. The median duration of Tamoxifen use was 43 months. Ovarian ablation was performed in $62(26 \%)$ premenopausal patients by open laparotomy or laparoscopic surgery in 34 patients and by radiotherapy in the remaining. All patients received some form of adjuvant systemic therapy except for seven patients registered during 1993.

At a median follow-up of 48 months, 126 (25.9\%) patients had relapsed. Thirteen $(2.7 \%)$ had local recurrence; six $(1.2 \%)$ had recurrence in regional lymph nodes and $107(22 \%)$ in distant organs. Bone was the commonest site of first metastatic recurrence in 32 patients followed by lung- 30 , liver -20 , brain -13 , nodes-seven, contralateral breast-two, skin-one, choroid - one and pericardium-one. At last follow-up, $354(72.7 \%)$ patients were alive and disease-free, 39 (8\%) were alive with disease and 94 (19.3\%) had died; $85(90.4 \%)$ had died due to disease progression, one due to chemotherapy toxicity and eight deaths were unrelated to breast cancer.

DFS and OS at five years were $73 \%$ and $78 \%$ respectively (Figures 1,2 ). In univariate analysis age, tumor size, nodal status, stage and number of positive lymph nodes emerged as significant factors (Table 2). When multivariate analysis of all significant factors was performed, lymph node status emerged as the only significant prognostic factor $(P<0.01)$, Figures 3 and 4 .

\section{Discussion}

Breast cancer accounts for $19-34 \%$ of all cancer cases among women nationally. ${ }^{[7-9]}$ As per the data from

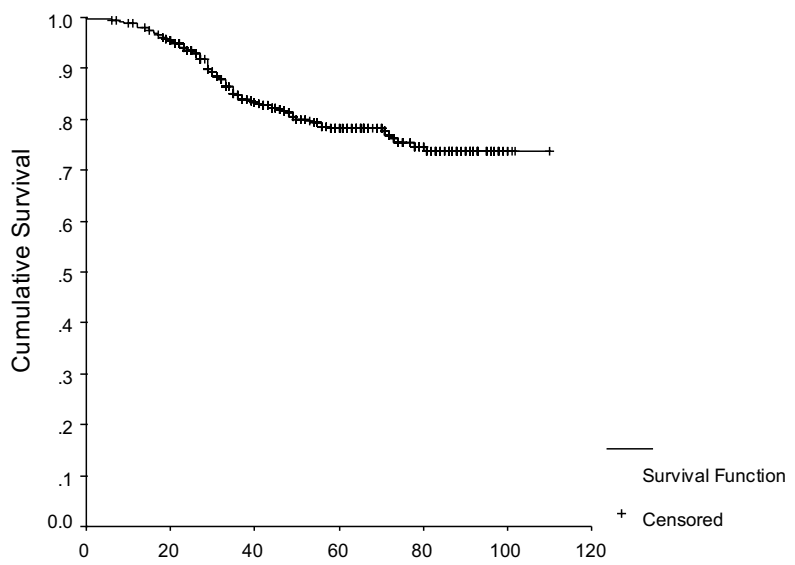

(a)

Time (months) national and regional cancer registries, it is the commonest cancer amongst women in Delhi, Mumbai, Ahmedabad, Kolkata and Trivandrum. ${ }^{[7-11]}$ In all other Indian registries, it is listed as the second leading site among women. The age-standardized incidence rates vary from 9-28.6 per 100,000 women, the lowest being from the rural area-based registry Barshi. ${ }^{[8]}$ The majority of the patients seek medical advice when the disease is fairly advanced. EBC constitutes only $30 \%$ of the breast cancer cases seen at regional cancer centers in India ${ }^{[3]}$ whereas it constitutes $60-70 \%$ of cases in the developed world. There is no prospective or retrospective published case series on EBC from India.

The median age at presentation was 47 years. The incidence rates in India begin to rise in the early thirties and peak at ages 50-64 years. ${ }^{[8]}$ In the US, rates peak at the age group of $75+$ years. Age-specific incidence rates in India remain relatively stable compared with the US where rates rise dramatically after 65 years of age. The lower age at diagnosis is also seen for other cancers in India, the reasons are not entirely clear but a major factor could be under-diagnosis and underreporting amongst the elderly population. ${ }^{[12]}$ There was equal distribution of pre- and post-menopausal women, $49 \%$ vs. $48 \%$ respectively. It is reported that whereas $73 \%$ of white female patients are postmenopausal at diagnosis, only $35 \%, 49 \%$, and $52 \%$ of Asian, black, and mixed-race patients, respectively, are postmenopausal.[13]

In our series, $16 \%$ patients had Stage I and $74 \%$ had Stage II disease. This is in contrast to that reported in studies from developed countries. In a study by Kemperman et $\mathrm{al}^{[14]} 58 \%$ of the patients with $\mathrm{EBC}$ had Stage I and 33\% had Stage II disease. Mansfield et $\mathrm{al}^{[15]}$ and Jacobson et al ${ }^{[16]}$ with $60 \%$ and $52 \%$ patients

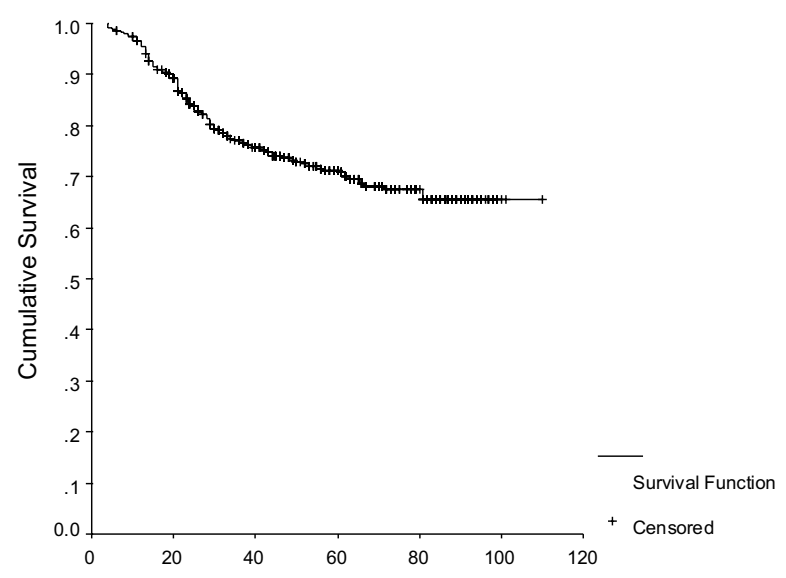

(b)

Figure 1: Kaplan-Meier curves of overall survival (a), and disease-free survival (b) for 487 early breast cancer cases 


\begin{tabular}{|c|c|c|c|c|c|c|c|}
\hline & Total & $\begin{array}{l}\text { Relapse } \\
\text { n (\%) }\end{array}$ & $\begin{array}{c}\text { Deaths } \\
\text { n (\%) }\end{array}$ & $\begin{array}{c}\text { DFS } \\
\text { Months }\end{array}$ & $P$ & $\begin{array}{c}\text { OS } \\
\text { Months }\end{array}$ & Is $P$ \\
\hline \multicolumn{8}{|c|}{ Menopausal status } \\
\hline Pre & 242 & $72(29.7)$ & $48(19.9)$ & 68 & NS & 79 & NS \\
\hline Post & 236 & $53(22.4)$ & $44(18.5)$ & 76 & & 76 & \\
\hline \multicolumn{8}{|l|}{ Age* } \\
\hline$<30$ & 21 & $10(47.6)$ & $8(38.1)$ & 42 & 0.01 & 57 & 0.04 \\
\hline $30-50$ & 285 & $80(28.0)$ & 54 (19.1) & 71 & & 79 & \\
\hline$>50$ & 181 & $36(20.0)$ & $31(17.1)$ & 79 & & 80 & \\
\hline \multicolumn{8}{|l|}{ Tumor size* } \\
\hline $\mathrm{T} 1$ & 134 & $23(17.1)$ & $14(10.4)$ & 82 & 0.03 & 87 & $<0.01$ \\
\hline $\mathrm{T} 2$ & 298 & $91(30.5)$ & $73(24.5)$ & 67 & & 74 & \\
\hline T3 & 29 & $6(20.6)$ & $5(17.2)$ & 82 & & 84 & \\
\hline $\mathrm{Tx}$ & 26 & $6(23.8)$ & $2(7.6)$ & 76 & & 90 & \\
\hline \multicolumn{8}{|c|}{ Nodal status* } \\
\hline No & 246 & $42(17.0)$ & $35(14.2)$ & 83 & $<0.01$ & 85 & 0.01 \\
\hline $\mathrm{N} 1$ & 217 & $74(34.1)$ & $54(25.0)$ & 62 & & 72 & \\
\hline $\mathrm{Nx}$ & 24 & $10(41.6)$ & $4(16.0)$ & 63 & & 81 & \\
\hline \multicolumn{8}{|l|}{ Stage ${ }^{*}$} \\
\hline 1 & 79 & $9(11.3)$ & $6(7.5)$ & 88 & $<0.01$ & 91 & $<0.01$ \\
\hline Ila & 180 & $38(21.1)$ & $32(17.7)$ & 78 & & 82 & \\
\hline $\mathrm{llb}$ & 183 & $64(34.9)$ & $49(26.90)$ & 64 & & 72 & \\
\hline Unknown & 45 & $15(33.3)$ & $6(13.0)$ & 67 & & 84 & \\
\hline \multicolumn{8}{|c|}{ No. Lymph-nodes* } \\
\hline 0 & 246 & $42(17.0)$ & $35(14.2)$ & 84 & & 86 & \\
\hline $1-3$ & 151 & $43(28.5)$ & $29(19.3)$ & 70 & $<0.01$ & 79 & $<0.01$ \\
\hline$\geq 4$ & 66 & $31(51.5)$ & $26(41.0)$ & 46 & & 58 & \\
\hline \multicolumn{8}{|l|}{ ER status } \\
\hline Positive & 93 & $19(20.4)$ & $11(11.8)$ & 79 & NS & 87 & NS \\
\hline Negative & 80 & $24(30)$ & $12(15.19)$ & 63 & & 81 & \\
\hline Unknown & 314 & $83(26.4)$ & $70(22.2)$ & 73 & & 76 & \\
\hline \multicolumn{8}{|l|}{ Surgery } \\
\hline MRM & 432 & $116(26.8)$ & $89(20.6)$ & 79 & NS & 77 & NS \\
\hline BCS & 55 & $10(18.1)$ & $4(7.2)$ & 72 & & 92 & \\
\hline
\end{tabular}

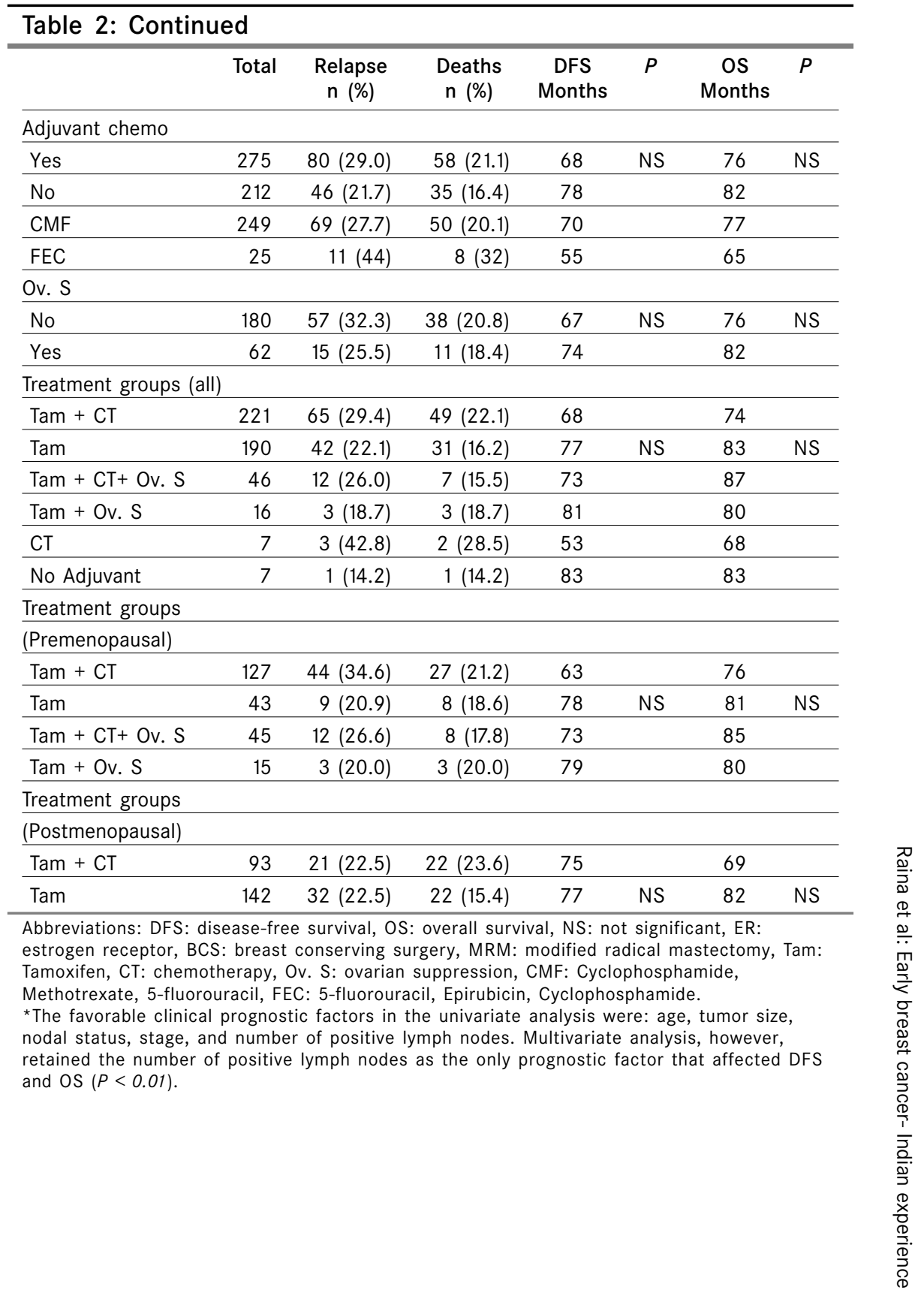




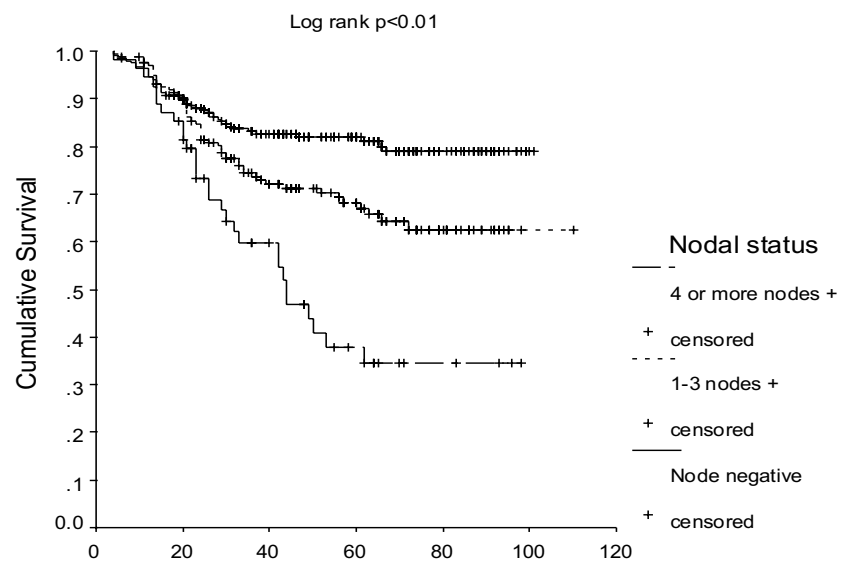

(a)

Time (months)

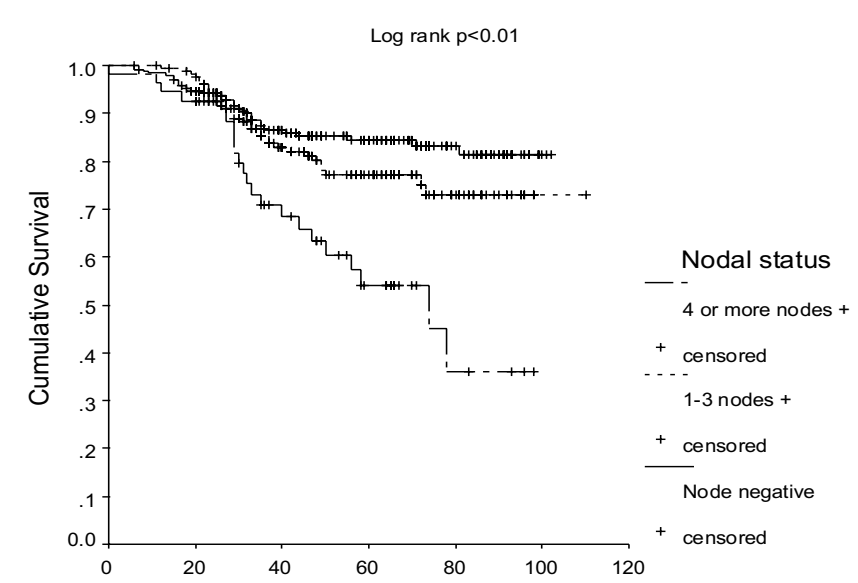

(b)

Time (months)

Figure 2: Kaplan-Meier curves of disease-free (a) and overall survival (b) for 487 patients with early breast cancer, depending upon the number of lymph nodes involved

with Stage I respectively also reported similar results. In almost all developed countries, the use of routine screening mammography has led to the detection of very early lesions. As mammographic facilities are not widely available here and there is no nation-wide breastscreening program, the commonest mode of presentation remains a lump in the breast, $96 \%$ of the patients in the present series presented with a breast lump. Besides this, other determinants like genetic, socioeconomic, cultural factors and accessibility to medical centers with cancer facilities and the dominance of traditional medicine practitioners in many areas has a major impact on incidence and survival.

Surgery was performed initially on all the patients. BCS was done in only $11 \%$ patients. The acceptance of BCS in India is different from that in the developed world. Data from the American College of Surgeons show that in $1995,58 \%$ of Stage I and $36 \%$ of Stage II cancers were treated by breast-sparing techniques. ${ }^{[17]}$ In an annual review of the United Kingdom National Screening Programme, the breast conservation rate in about 6000 screen-detected cancers was $75 \% .{ }^{[18]}$ In a study from our center, BCS was offered to 200 suitable breast cancer patients between June 1993 and June 1998; $25 \%$ opted for breast conservation and the remaining preferred mastectomy. ${ }^{[19]}$ Over the past five to six years, however, the trend is changing especially in the urban areas, as more women are opting for breast conservation. ER status was not routinely tested in our patients during the earlier part of the study period, hence this information is available in only $35 \%$ of patients, $53 \%$ of these being positive. In previous two studies from India by Raina et $\mathrm{al}^{[20]}$ and Redkar et al, ${ }^{[21]}$ ER positivity was shown to be $50.5 \%$ and $43.9 \%$, respectively. At least $60-80 \%$ of the patients are found to be ER-positive in the studies reported from Europe and America. ${ }^{[22,23]}$ These differences in receptor distribution between Indian and Caucasian patients might be attributed to either lower average age at diagnosis of Indian patients or real racial differences. CMF was the preferred chemotherapy because it was more cost-effective, however, of late this trend has changed and anthracycline-based chemotherapy has become the standard.

We observed first recurrences at loco-regional sites in $4 \%$ of the patients as compared with $22 \%$ in metastatic sites. In an EORTC trial, the actuarial recurrence at eight years was nine per cent in Stage I and Stage II patients treated with surgery followed by RT. ${ }^{[24]}$ In the Milan trial, loco-regional recurrence following postoperative RT and CT was $11 \% \cdot{ }^{[25]}$ Our lower rate of loco-regional recurrences may be due to more frequent practice of mastectomy. For the whole cohort of patients, DFS and OS in our study were $73 \%$ and $78 \%$ respectively. Patients with Stage I had DFS and OS of $88 \%$ and $91 \%$ respectively while the corresponding figures for Stage II A were $78 \%$ and $82 \%$ and that for II B $64 \%$ and $72 \%$. These figures are consistent with the five-year relative survival rates of $98 \%, 88 \%$, and $76 \%$ for Stages I, II A and II B, respectively as per American Cancer Society statistics.

In conclusion, breast cancer is a major public health problem in India. Late presentation is a major concern, as large numbers of EBC patients are still diagnosed in clinical Stage II. Patient preference for mastectomy is an important reason for the under-utilization of breast conservation therapy. Education/awareness campaigns, improvement of socioeconomic conditions, better access to diagnostic resources, availability of higher standards 
of health care, use of breast self-examination, and screening mammography if implemented nationally would go a long way towards increasing early diagnosis and improved survival with a consequent possible rise in incidence of early cases as is happening in the West.

\section{References}

1. Ferlay J, Bray F, Pisani P, Parkin DM. Globocan 2002: Cancer Incidence, Mortality and Prevalence Worldwide. IARC Cancer Base No. 5. Version 2.0, IARC Press, Lyon, 2004. Available from: http:/ /www-dep.iarc.fr/.

2. Parkin DM, Pisani P, Ferlay J. Global cancer statistics. CA Cancer J Clin 1999;49:33-64.

3. Goel AK, Seenu V, Shukla NK, Raina V. Breast cancer presentation at a regional cancer center. Natl Med J India 1995;8:6-9.

4. Gajalakshmi CK, Shanta V, Swaminathan R, Sankaranarayanan $\mathrm{R}$, Black RJ. A population-based survival study on female breast cancer in Madras, India. Br J Cancer 1997;75:771-5.

5. Nandakumar A, Anantha N, Venugopal TC, Sankaranarayanan R, Thimmasetty K, Dhar M. Survival in breast cancer: A populationbased study in Bangalore, India. Int J Cancer 1995;60:593-6.

6. Sobin LH, Wittekind Ch., editors. UICC TNM Classification of malignant tumors. $5^{\text {th }}$ Ed. New York: John Wiley \& Sons, Inc.; 1997.

7. National Cancer Registry Programme. Ten year consolidated report of the hospital based cancer registries 1984-1993. An assessment of the burden and care of cancer patients. New Delhi: Indian Council of Medical Research; 2001.

8. National Cancer Registry Programme. Consolidated report of the population based cancer registries 1990-1996. New Delhi: Indian Council of Medical Research; 2001.

9. National Cancer Registry Programme. Consolidated report of the population based cancer registries 1990-1996. Supplement: Yearwise tabulation of incident cancers and rates by site and gender. New Delhi: Indian Council of Medical Research; 2001.

10. Sen U, Sankaranarayanan R, Mandal S, Ramanakumar AV, Parkin DM, Siddiqi M. Cancer patterns in eastern India: the first report of the Kolkata cancer registry. Int J Cancer 2002; 100:86-91.

11. Parkin DM, Whelan SL, Ferlay J, Raymond, L, Young J, editors. Cancer Incidence in Five Continents. Vol VII. IARC Scientific Publication 143. Lyon: International Agency for Research on Cancer; 1997.

12. Bhutani M, Vora A, Kumar L, Kochupillai V. Lympho-hemopoietic malignancies in India. Med Oncol 2002;19:141-50.

13. Pegoraro RJ, Nirmul D, Bryer JV, Jordaan JP, Joubert SM. Clinical patterns of presentation of breast cancer of different racial groups in South Africa. S Afr Med J 1985;68:808-10.

14. Kemperman $\mathrm{H}$, Borger J, Hart A, Peterse $\mathrm{H}$, Bartelink $\mathrm{H}$, van Dongen J. Prognostic factors for survival after breast conserving therapy for stage I and II breast cancer. The role of local recurrence. Eur J Cancer 1995;31A:690-8.

15. Mansfield CM, Komarnicky LT, Schwartz GF, Rosenberg AL, Krishnan L, Jewell WR, et al. Cancer 1995;75:2328-36.

16. Jacobson JA, Danforth DN, Cowan KH, d'Angelo T, Steinberg SM, Pierce L, et al. Ten-year results of a comparison of conservation with mastectomy in the treatment of stage I and II breast cancer. N Engl J Med 1995;332:907-11.

17. Bland KI, Menck HR, Scott-Conner CE, Morrow M, Winchester DJ, Winchester DP. The National Cancer Data Base 10-year survey of breast carcinoma treatment at hospitals in the United States. Cancer 1998;83:1262-73.

18. NHS Breast Screening Programme and British Association of Surgical Oncology. Audit of screen detected breast cancers 19971998. NHS Breast Screening Programme, 1999.

19. Deo SS, Mohanti BK, Shukla NK, Chawla S, Raina V, Julka PK, et al. Attitudes and treatment outcome of breast conservation therapy for stage I and II breast cancer using peroperative iridium-192 implant boost to the tumour bed. Australas Radiol 2001;45:35-8.

20. Raina V, Taneja V, Gulati A, Deo SVS, Shukla NK, Vij U, et al. Oestrogen receptor status in breast cancer. Indian Pract 2000;53:405-7.

21. Redkar AA, Kabre SS, Mittra I. Estrogen and progesterone receptors measurement in breast cancer with enzyme-immunoassay and correlation with other prognostic factors. Indian J Med Res 1992;96:1-8.

22. Biesterfeld S, Schroder W, Steinhagen G, Koch R, Veuskens U, Schmitz FJ, et al. Simultaneous immunohistochemical and biochemical hormone receptor assessment in breast cancer provides complementary prognostic information. Anticancer Res 1997; 17:4723-9.

23. Li Cl, Daling JR, Malone KE. Incidence of invasive breast cancer by hormone receptor status from 1992 to 1998. J Clin Oncol 2003;21:28-34

24. van Dongen JA, Bartelink H, Fentiman IS, Lerut T, Mignolet F, Olthuis $\mathrm{G}$, et al. Factors influencing local relapse and survival and results of salvage treatment after breast-conserving therapy in operable breast cancer: EORTC trial 10801, breast conservation compared with mastectomy in TNM stage I and II breast cancer. Eur J Cancer 1992;28A:801-5.

25. Bonadonna G, Valagussa P, Rossi A, Tancini G, Brambilla C, Zambetti M, et al. Ten-year experience with CMF-based adjuvant chemotherapy in resectable breast cancer. Breast Cancer Res Treat 1985;5:95-115. 